\title{
Specific mutations in KRAS codon 12 are associated with worse overall survival in patients with advanced and recurrent colorectal cancer
}

\begin{abstract}
Robert P Jones ${ }^{*, 1,2}$, Paul A Sutton ${ }^{2,3}$, Jonathan P Evans ${ }^{2,3}$, Rachel Clifford ${ }^{4}$, Andrew McAvoy ${ }^{1}$, James Lewis ${ }^{3}$, Abigail Rousseau ${ }^{5}$, Roger Mountford ${ }^{5}$, Derek McWhirter ${ }^{1,2}$ and Hassan Z Malik ${ }^{1}$

${ }^{1}$ North Western Hepatobiliary Unit, Aintree University Hospital, Liverpool, UK; ${ }^{2}$ School of Cancer Studies, Institute of Translational Medicine, University of Liverpool, Liverpool, UK; ${ }^{3}$ Department of Surgery, Wirral University Teaching Hospital NHS Foundation Trust, Cheshire, UK; ${ }^{4}$ Department of Surgery, St. Helens and Knowsley Teaching Hospitals NHS Trust, Merseyside, UK and ${ }^{5}$ Regional Molecular Genetics Laboratory, Liverpool Women's NHS Foundation Trust, Liverpool, UK
\end{abstract}

Background: Activating mutations in KRAS have been suggested as potential predictive and prognostic biomarkers. However, the prognostic impact of specific point mutations remains less clear. This study assessed the prognostic impact of specific KRAS mutations on survival for patients with colorectal cancer.

Methods: Retrospective review of patients KRAS typed for advanced and recurrent colorectal cancer between 2010 and 2015 in a UK Cancer Network.

Results: We evaluated the impact of KRAS genotype in 392 patients. Mutated KRAS was detected in $42.9 \%$ of tumours. KRAS mutations were more common in moderate vs well-differentiated tumours. On multivariate analysis, primary tumour T stage (HR 2.77 (1.54-4.98), $P=0.001$ ), $N$ stage (HR $1.51(1.01-2.26), P=0.04)$, curative intent surgery (HR $0.51(0.34-0.76), P=0.001$ ), tumour grade (HR 0.44 (0.30-0.65), $P=0.001$ ) and KRAS mutation (1.54 (1.23-2.12), $P=0.005)$ were all predictive of overall survival. Patients with KRAS codon 12 mutations had worse overall survival (HR 1.76 (95\% Cl 1.27-2.43), $P=0.001)$. Among the five most common codon 12 mutations, only p.G12C (HR $2.21(1.15-4.25), P=0.01)$ and p.G12V (HR 1.69 (1.08-2.62), $P=0.02)$ were predictive of overall survival.

Conclusions: For patients with colorectal cancer, p.G12C and p.G12V mutations in codon 12 were independently associated with worse overall survival after diagnosis.

Colorectal cancer represents a heterogeneous group of diseases, and its molecular classification is increasingly important. A number of key genetic and epigenetic alterations have been identified (Colussi et al, 2013; Kudryavtseva et al, 2016), with early activating mutations in the KRAS gene reported in $\sim 40 \%$ of tumours (Downward, 2003).
KRAS is a protein and downstream effector of epidermal growth factor receptor (EGFR), with binding of the EGF ligand to the receptor triggering downstream signalling via the PI3K/AKT/ MTOR and RAF/MEK/ERK cellular proliferation pathways (Fearon, 2011). Approximately $90 \%$ of mutations occur within codon 12 and 13 (Janakiraman et al, 2010), with well-characterised

*Correspondence: RP Jones; E-mail: robjones@liv.ac.uk

Received 15 December 2016; revised 19 January 2017; accepted 24 January 2017; published online 16 February 2017

(C) 2017 Cancer Research UK. All rights reserved 0007-0920/17 
single-base substitution point mutations (Neumann et al, 2009). Patterns of KRAS mutation vary according to tumour location, with KRAS mutations twice as common in lesions proximal to the splenic flexure (Rosty et al, 2013). This concept of distinct genetic and epigenetic profiles of proximal and distal lesions was further evolved with the finding that the frequencies of CIMP-high, MSIhigh and BRAF mutation gradually increased from rectum to ascending colon, suggesting the classic proximal $v s$ distal classification may be oversimplistic (Yamauchi et al, 2012). By contrast, KRAS mutations did not follow this trend but were most common in caecal lesions.

The predictive role of KRAS mutation on efficacy of anti-EGFR therapy is well recognised. However, reports on prognostic value remain uncertain. It is now recognised that specific point mutations can have profoundly differing effects on KRAS function. It was long assumed that any KRAS mutation meant patients derived no advantage from treatment with anti-EGFR therapies, but there is now growing evidence that those with specific mutations in codon 13 (p.G13D) may derive a survival benefit in contrast to patients with codon 12 mutations (De Roock et al, 2010; Tejpar et al, 2012). These fundamental differences in tumour phenotype within the KRAS-mutant population have lead to a reassessment of the prognostic value of KRAS mutations. Numerous studies have compared outcomes in patients with codon 12,13 and 61 mutations, with mixed results (Samowitz et al, 2000; Andreyev et al, 2001; Bazan et al, 2002; Roth et al, 2010; Yokota et al, 2011; Imamura et al, 2012, 2014). However, these studies group mutations by codon and so the impact of specific amino acid changes remains unclear. Laboratory studies have suggested that specific KRAS point mutations in codon 12 may confer increased oncogenic potential through the inhibition of apoptosis, loss of contact inhibition and increased contact-independent growth when compared to codon 13 mutations (Al-Mulla et al, 1999; Guerrero et al, 2000; Smith et al, 2010), but the clinical relevance of these findings have yet to be clarified.

This study therefore aimed to assess the prognostic impact of specific point mutations in KRAS on overall survival in a mixed cohort of advanced and recurrent colorectal cancer patients.

\section{MATERIALS AND METHODS}

Study design. Patients who underwent KRAS typing on surgically resected or biopsied specimens between May 2010 and February 2015 in the Cheshire and Merseyside Cancer Network were identified from a prospectively collected database. Standard demographic and clinicopathological data were retrieved from paper and electronic case notes on each patient including age, sex, ASA grade, tumour location, stage and grade at presentation (date of curative intent surgery if appropriate, or date of diagnosis with irresectable disease), surgical management, date of last follow-up, date and pattern of recurrence, and date of death. Surgery was considered curative when all identifiable disease was resected with curative intent. Patients were treated with systemic chemotherapy according to contemporary NICE guidance (first-line treatment with systemic FOLFOX; Poston et al, 2011). Survival was calculated from date of curative intent surgery or presentation with irresectable metastatic disease to date of last follow-up. Where synchronous metastatic disease was resected with curative intent, survival time was calculated from date of final resection.

KRAS mutation analysis. KRAS testing was performed centrally in the Merseyside \& Cheshire Regional Genetics Laboratories using resected or biopsied primary colorectal cancer. DNA was extracted using standard methodology from formalin-fixed paraffin-embedded tumour samples and analysed for mutations in codons 12, 13 and 61 of the KRAS gene using a Pyrosequencing-based assay (Qiagen,
Venlo, The Netherlands), capable of detecting all somatic mutations in codons 12, 13 and 61 of the KRAS gene. The assay will detect all possible base substitutions at the specified codons plus more complex insertion-deletion mutations, with a limit of detection of $5-10 \%$ mutant DNA (dependent on the base substitution identified).

Statistical analysis. Demographic, clinicopathological and perioperative details were stratified according to KRAS mutation. Quantitative and qualitative variables were expressed as medians (with range) and frequencies. Comparisons between the groups were analysed with the $\chi^{2}$-test or Fisher exact test for proportions and the Mann-Whitney $U$-test for continuous variables. Overall- and disease-free survival were compared using the Kaplan-Meier method. Comparisons were made using log-rank test. To identify factors associated with survival in the entire cohort, variables were assessed using univariate analysis. All variables associated with $P<0.05$ in the univariate proportional hazards model were entered into a Cox proportional hazards multivariate model using a forward step wise procedure. $P<0.05$ was considered significant. All statistical analyses were performed using IBM SPSS Statistics (v.22, Armonk, NY, USA).

\section{RESULTS}

Frequency of KRAS mutations and association with clinicopathological factors. The total study population consisted of 495 patients in whom KRAS data were available. KRAS mutations were identified in $40 \%(n=198)$ of samples, with the majority $(31.5 \%$, $n=156)$ in codon 12 and codon $13(7.3 \%, n=36)$. Only $1.2 \%$ $(n=6)$ had a mutation in codon 61.

About $392(79.2 \%)$ patients in whom adequate retrospective data could be obtained were further assessed for clinicopathological and survival analysis. Table 1 summarises the baseline clinicopathological characteristics of these patients stratified by KRAS mutation status. KRAS mutations were present in $(42.9 \%$, $(n=168)$, with the majority occurring in codon $12(34.6 \%$, $n=136)$ and $13(7.1 \%, n=28)$. Within codon 12 , p.G12D was the most common point mutation (36.0\%, $n=49$ out of 136) followed by p.G12V $(30.1 \%, n=41$ out of 136$)$. Within codon 13 , p.G13D was most common $(92.9 \%, n=26$ out of 28$)$. All other codon 12 and 13 mutations had a frequency $<10 \%$ (Table 2 ).

Median patient age was 65.2 years (IQR 25-78) and most patients were female $(n=242,61.7 \%)$. Most patients had a colonic primary tumour ( $n=243,61.9 \%$ ), with the majority of lesions demonstrating moderately differentiated adenocarcinoma $(n=282,71.9 \%)$. There was no difference in frequency of KRAS mutation and site of primary lesion. Of the 298 patients who had undergone curative intent surgery, $76 \%(n=226)$ developed recurrence. Of those 226, $64(21.5 \%)$ underwent resection of recurrent disease. Fifty-eight were treated with liver resection, five underwent lung resection and one underwent a further colorectal procedure for local recurrence. KRAS mutation was significantly correlated only with tumour grade $(P=0.01)$, and was not associated with stage at presentation, pattern of metastases or curative intent surgery (Table 2). The presence of a KRAS 12 mutation was not associated with any specific clinicopathological characteristics. When codon 61 mutations were excluded from analysis, no differences were observed between patients with wild-type KRAS and mutations in codon 12 or 13 .

Overall survival. At a median follow-up of 22 months (IQR 3-100 months), 220 patients (56.1\%) had died. Median overall survival for the entire patient cohort was 31.3 (IQR 28.6-33.9) months, with a nominal 1-, 3- and 5-year survival of $82 \%, 41 \%$ and $17 \%$, respectively.

Univariate analysis identified stage and grade of tumour, curative intent surgery, pattern of metastasis and KRAS status as predictive of overall survival (Table 3). On multivariate analysis controlling for other factors, KRAS status remained statistically 
Table 1. Association of clinicopathological features with KRAS mutational status

\begin{tabular}{|c|c|c|c|c|c|}
\hline \multicolumn{2}{|r|}{ KRAS WT } & \multicolumn{3}{|c|}{ KRAS mutant } & $P$-value \\
\hline \multicolumn{6}{|l|}{ Gender } \\
\hline Male & $91(40.6 \%)$ & 47 (34.6\%) & $9(32.1 \%$ & $3(75.0 \%)$ & \multirow[t]{2}{*}{0.26} \\
\hline Female & $133(59.4 \%)$ & 89 (65.4\%) & 19 (67.9\%) & $1(25.0 \%)$ & \\
\hline 2 & 114 (50.9\%) & 73 (53.7\%) & 18 (64.3\%) & $1(25.0 \%)$ & \multirow{2}{*}{0.70} \\
\hline 3 & $33(14.7 \%)$ & $16(11.8 \%)$ & $2(7.1 \%)$ & $1(25.0 \%)$ & \\
\hline \multicolumn{6}{|l|}{ Curative intent surgery } \\
\hline Yes & 168 (75.0\%) & 106 (77.9\%) & $20(71.4 \%)$ & $4(100.0 \%)$ & \multirow[t]{2}{*}{0.58} \\
\hline No & $56(25.0 \%)$ & $30(22.1 \%)$ & $8(28.6 \%)$ & $0(0 \%)$ & \\
\hline \multicolumn{6}{|l|}{$\mathrm{N}$ stage } \\
\hline 0 & 48 (21.4\%) & $44(32.4 \%)$ & $6(21.4 \%)$ & $2(50.0 \%)$ & \multirow[t]{3}{*}{0.13} \\
\hline 1 & $80(35.7 \%)$ & $50(36.8 \%$ & $8(28.6 \%)$ & 1 (25.0\%) & \\
\hline 2 & $96(42.9 \%)$ & $42(30.9 \%)$ & $14(50.0 \%)$ & $1(25.0 \%)$ & \\
\hline \multicolumn{6}{|l|}{$M$} \\
\hline 0 & $121(54.0 \%)$ & $76(55.9 \%)$ & $13(46.4 \%)$ & $4(100 \%)$ & \multirow[t]{2}{*}{0.24} \\
\hline 1 & $103(46.0 \%)$ & $60(44.1 \%)$ & $15(53.6 \%)$ & $0(0 \%)$ & \\
\hline \multicolumn{6}{|l|}{ Grade } \\
\hline NA & $17(7.6 \%)$ & $12(8.8 \%)$ & $2(7.1 \%)$ & $0(0.0 \%)$ & \multirow{3}{*}{0.01} \\
\hline Poor & 30 (13.4\%) & $10(7.4 \%)$ & $3(10.7 \%)$ & $1(25.0 \%)$ & \\
\hline Moderate & 166 (74.1\%) & 91 (66.9\%) & 22 (78.6\%) & 3 (75.0\%) & \\
\hline No recurrence & $52(23.2 \%)$ & $29(21.3 \%)$ & 7 (25.0\%) & $1(25.0 \%)$ & \multirow[t]{5}{*}{0.80} \\
\hline Liver only & 88 (39.3\%) & 45 (33.1\%) & $8(28.6 \%)$ & $1(25.0 \%)$ & \\
\hline Lung only & $22(9.8 \%)$ & $11(8.1 \%)$ & $2(7.1 \%)$ & $1(25.0 \%)$ & \\
\hline Liver and lung only & 23 (10.3\%) & 21 (15.4\%) & 4 (14.3\%) & $1(25.0 \%)$ & \\
\hline Widespread & 39 (17.4\%) & $30(22.1 \%)$ & 7 (25.0\%) & $0(0.0 \%)$ & \\
\hline
\end{tabular}

\section{Table 2. Frequency of KRAS mutations}

\begin{tabular}{|l|l|}
\hline Somatic mutation & $\boldsymbol{N}(\%)$ \\
\hline c.35G $>$ A p.G12D & $49(29.2 \%)$ \\
\hline c.35G > C p.G12A & $15(8.9 \%)$ \\
\hline c.34G $>$ T p.G12C & $15(8.9 \%)$ \\
\hline c.34_35delinsTT p.G12F & $1(0.6 \%)$ \\
\hline c.34G $>$ A p.G12S & $16(9.5 \%)$ \\
\hline c.35G $>$ T p.G12V & $41(24.4 \%)$ \\
\hline c.38G $>$ A p.G13D & $26(15.5 \%)$ \\
\hline c.37G $>$ T p.G13C & $2(1.2 \%)$ \\
\hline c.183A $>$ T p.Q61H & $4(2.4 \%)$ \\
\hline
\end{tabular}

significant (HR 1.54 (95\% CI 1.23-2.12), $P=0.005)$. Median overall survival for patients with wild-type KRAS was 35.1 months compared with 25.8 for those with mutant KRAS $(P=0.006)$. Median overall survival for patients with mutations in codon 12 and codon 13 was 24.8 and 22.4 months, respectively $(P=0.002$ for codon 12, $P=0.08$ for codon 13; Figure 1). Multivariate analysis confirmed patients with mutations in codon 12 had worse OS (HR 1.76 (95\% CI 1.27-2.43, $P=0.001$ ). In contrast, mutations in codon 13 did not appear to impact on survival (HR 1.7 (95\% CI 0.93-3.46, $P=0.06$ ).

The five most commonly identified codon 12 mutations were then further analysed, with worse overall survival associated with p.G12V (univariate HR 1.69 (95\% CI 1.08-2.62, $P=0.02$ ) and p.G12C (univariate HR 2.21 (95\% CI 1.15-4.25, $P=0.01$ ) point mutations (Table 4). Patients with p.G12V $(n=41)$ and p.G12C $(n=15)$ mutations both had a median survival of 24.9 months compared with 35.1 months for wild-type KRAS ( $P<0.02$; Figure 2$)$.

\section{DISCUSSION}

This study assessed the impact of KRAS mutation on prognosis in advanced and recurrent colorectal cancer. Within our cohort, 
Table 3. Univariate and multivariate analysis of overall survival stratified by clinicopatholgical features

\begin{tabular}{|c|c|c|c|c|}
\hline & \multicolumn{4}{|c|}{ Hazard ratio $(95 \% \mathrm{Cl})$} \\
\hline Age $>65$ & $1.14(0.87-1.34)$ & 0.32 & & \\
\hline$A S A>3$ & $0.92(0.75-1.13)$ & 0.42 & & \\
\hline \multicolumn{5}{|c|}{ AJCC stage at presentation } \\
\hline \multicolumn{5}{|l|}{ Location } \\
\hline $\begin{array}{l}\text { Caecum } \\
\text { Ascending } \\
\text { Transverse } \\
\text { Descending } \\
\text { Rectum } \\
\text { Curative intent surgery }\end{array}$ & $\begin{array}{c}1 \text { (Reference) } \\
0.89(0.67-1.2) \\
0.94(0.56-2.63) \\
1.02(0.87-1.54) \\
0.76(0.54-1.76) \\
0.29(0.22-0.39)\end{array}$ & $\begin{aligned} & 0.23 \\
& 0.12 \\
& 0.3 \\
& 0.15 \\
< & 0.001\end{aligned}$ & $0.51(0.34-0.76)$ & 0.001 \\
\hline \multicolumn{5}{|l|}{ Tumour grade } \\
\hline $\begin{array}{l}\text { Poor } \\
\text { Moderate } \\
\text { Well }\end{array}$ & $\begin{array}{r}1 \text { (Reference) } \\
0.49(0.34-0.72) \\
0.57(0.32-1.02)\end{array}$ & $\begin{array}{c}<0.001 \\
0.59\end{array}$ & $0.44(0.30-0.65)$ & 0.001 \\
\hline \multicolumn{5}{|l|}{ Metastatic site } \\
\hline $\begin{array}{l}\text { None } \\
\text { Liver only } \\
\text { Lung only } \\
\text { Liver/lung only } \\
\text { Widespread }\end{array}$ & $\begin{array}{r}1 \text { (Reference) } \\
2.49(1.59-3.90) \\
1.27(0.69-2.34) \\
2.88(1.72-4.81) \\
2.71(1.68-4.34)\end{array}$ & $\begin{array}{c}<0.001 \\
0.43 \\
<0.001 \\
<0.001\end{array}$ & $\begin{array}{l}1.33(0.80-2.21) \\
1.13(0.62-2.05) \\
1.21(0.71-2.07)\end{array}$ & $\begin{array}{l}0.27 \\
0.69 \\
0.47\end{array}$ \\
\hline \multicolumn{5}{|l|}{ KRAS } \\
\hline $\begin{array}{l}\text { Wild type } \\
\text { Mutant } \\
\text { All codon } 12 \text { mutants } \\
\text { All codon } 13 \text { mutants } \\
\text { All codon } 61 \text { mutants }\end{array}$ & $\begin{array}{r}1 \text { (Reference) } \\
1.48(1.11-1.96) \\
1.55(1.17-2.07) \\
1.65(0.89-2.68) \\
0.85(0.21-3.44)\end{array}$ & $\begin{array}{l}0.007 \\
0.002 \\
0.06 \\
0.82\end{array}$ & $\begin{array}{r}1.54(1.23-2.12) \\
1.76(1.27-2.43) \\
1.7(0.93-3.46)\end{array}$ & $\begin{array}{l}0.005 \\
0.001 \\
0.06\end{array}$ \\
\hline
\end{tabular}

A

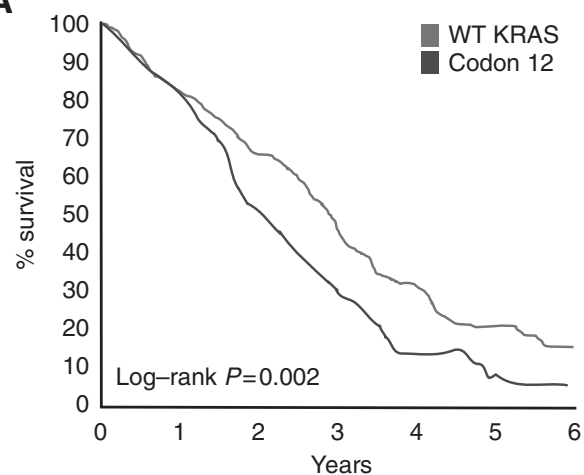

No. at risk

WT $224 \quad 158 \quad 101 \quad 45 \quad 19 \quad 12 \quad 7$
B

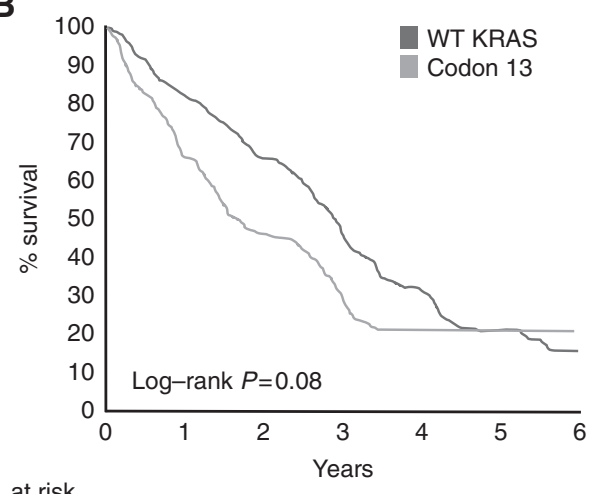

No. at risk

$\begin{array}{lllllll}\text { WT } 224 & 158 & 101 & 45 & 19 & 12 & 7\end{array}$

Figure 1. Overall survival for patients with advanced or recurrent colorectal cancer stratified by codon mutation (A) Wild type vs codon 12 (B) Wild type vs codon 13.

mutations in KRAS codon 12 were independently associated with a worse OS when compared with KRAS wild-type tumours. By contrast, mutations in codon 13 were not associated with worse OS. When outcome was further stratified by specific point mutations within codon 12, p.G12C and p.G12V mutations were both independently associated with worse OS compared with $K R A S$ wild-type tumours.
KRAS mutations were identified in $42.9 \%$ of patients included for survival analysis, similar to other reports of both stage III and IV colorectal cancer (Yokota et al, 2011; Yoon et al, 2014), with similar rates of p.G12C (8.9 vs 10.0\%) and p.G12V (24.4 vs 21.1\%) mutation (Imamura et al, 2012). Rates of codon 61 mutation were low (1.5\%), in keeping with other published series (Imamura et al, 2014). The advanced and recurrent nature of this patient cohort 
implies more aggressive disease, with lower rates of KRAS mutation in general and p.G12V and p.G12C mutations in particular reported in groups of patients with earlier stage disease and longterm disease-free survival (Margonis et al, 2015).

Although the predictive role of KRAS is well recognised, its precise prognostic value remains controversial. Mutations in KRAS have been clearly demonstrated to confer resistance to systemic anti-EGFR therapies in large prospective studies (Van Cutsem et al, 2009, 2011; Bokemeyer et al, 2009). However, retrospective reports on the prognostic value of KRAS have failed to provide a clear answer (Samowitz et al, 2000; Castagnola and Giaretti, 2005). One potential source of error may be that most historical reports have compared KRAS wild type with any KRAS mutant, rather than mutations in specific codons. There is growing recognition that specific mutations in KRAS may alter tumour phenotype. For example, retrospective subgroup analysis of large randomised trials of anti-EGFR therapy have identified that in contrast with other KRAS-mutant patients, those with p.G13D mutations may actually derive benefit from anti-EGFR therapy (Tejpar et al, 2012). Somatic mutations in codon 12 and 13 have also been associated with more aggressive stage at presentation and worse DFS in resected stage III colon cancer and OS in stage IV colorectal cancer compared with wild-type disease (Andreyev et al, 2001; Yokota et al, 2011; Imamura et al, 2012; Yoon et al, 2014; Li et al, 2015). However, the prognostic value of specific point mutations has not yet been fully clarified.

This study clearly demonstrates that p.G12C (HR 2.21 (95\% CI $1.15-4.25), P=0.01$ ) and p.G12V (HR 1.69 (95\% CI 1.08-2.62), $P=0.02$ ) were both strongly associated with worse overall survival. By contrast, other mutations in codon 12 and mutations in codon 13 and 61 did not impact on survival. These data are consistent with previous laboratory studies, which have suggested that

Table 4. Univariate analysis of overall survival according to codon 12 KRAS mutation

\begin{tabular}{|l|c|l|}
\hline Somatic mutation & Univariate hazard ratio & $P$-value \\
\hline WT & 1 (Reference) & \\
\hline c.35G > A p.G12D & $1.28(0.84-1.94$ & 0.24 \\
\hline c.35G > C p.G12A & $1.90(0.99-3.68)$ & 0.05 \\
\hline c.34G > T p.G12C & $2.21(1.15-4.25)$ & 0.01 \\
\hline c.34G > A p.G12S & $1.43(0.77-2.67)$ & 0.26 \\
\hline c.35G > T p.G12V & $1.69(1.08-2.62)$ & 0.02 \\
\hline Abbreviation: Wt $=$ wild type. & \\
\hline
\end{tabular}

\section{A}

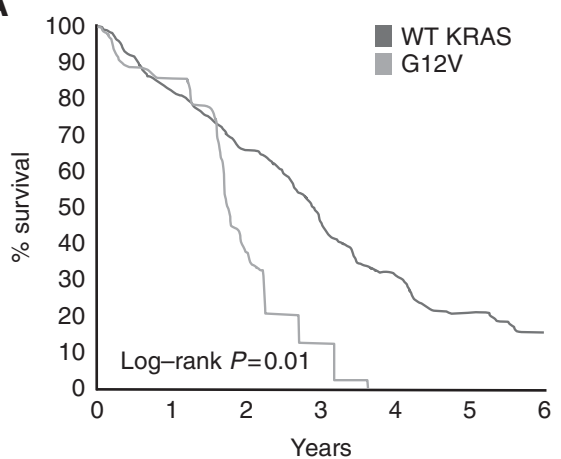

No. at risk

\begin{tabular}{|c|c|c|c|}
\hline WT 224 & 158 & 101 & 45 \\
\hline $2 \mathrm{~V} 4$ & 31 & 13 & 3 \\
\hline
\end{tabular}

mutations in KRAS codon 12 confer a greater oncogenic capacity (Guerrero et al, 2000) and are in keeping with the concept that mutations in a single gene can lead to a specific tumour phenotype (Ogino et al, 2012). The negative impact of codon 12 mutation is also biologically plausible. Binding of GTP to KRAS results in protein activation, triggering downstream signalling and cellular proliferation. The enzyme GTPase regulates this process, causing KRAS-GTP deactivation and is regulated by Rho-GTPase-activating proteins and Rap guanine-nucleotide exchange factors (Karnoub and Weinberg, 2008). RAS mutants are resistant to this GTPase-controlled regulatory step, with mutations in codon 12 associated with higher thresholds for induction of apoptosis (Guerrero et al, 2000). Specifically, p.G12V mutations have been associated with more aggressive cellular transformation than other codon 12 mutations in vitro, in keeping with the findings of this study (Al-Mulla et al, 1999).

This study found no correlation between clinicopathological disease features, including tumour location and KRAS status, in contrast to other larger series, which identified higher rates of KRAS mutation in proximal disease (Cancer Genome Atlas Network, 2012; Yamauchi et al, 2012; Yoon et al, 2014). Proximal disease does appear to be more aggressive, with patients undergoing curative surgery for proximal tumours who develop recurrence less likely to be treatable with curative intent (Pugh et al, 2016). These apparently contradictory findings highlight the complex interplay between aberrant pathways in the pathogenesis of colorectal cancer.

Strengths of this study include a relatively large cohort of patients with advanced and recurrent colorectal cancer managed in contemporary Western practice. It also provides an accurate description of mutational frequency in metastatic colorectal cancer outside a selective clinical trial. Direct interrogation of patient notes, rather than reliance on clinical coding, also ensured a high degree of clinical accuracy.

Weaknesses of the study include the lack of testing for BRAF codon 600 mutations (a downstream molecule of KRAS), which is known to be a very poor prognostic indicator (Yokota et al, 2011). However, KRAS and BRAF mutations are recognised as being mutually exclusive, $B R A F$ codon 600 mutations have a relatively low incidence $(<10 \%)$ in Western populations (Rajagopalan et al, 2002) and it is well recognised that the respective malignancy of the codon 12 and 13 mutations is independent of BRAF (Colussi et al, 2013). Given the consistently demonstrated negative prognostic impact of BRAF codon 600 mutations on patient survival (Roth et al, 2010; Yokota et al, 2011) and their potential inclusion in the KRAS wild-type cohort, inclusion of BRAF-mutant

\section{B}

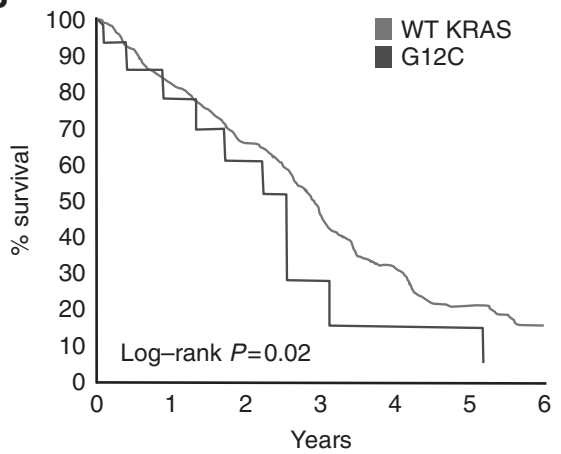

No. at risk

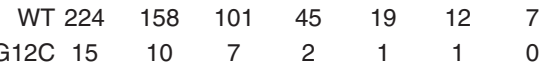

Figure 2. Overall survival for patients with advanced or recurrent colorectal cancer stratified by codon 12 point mutation (A) Wild type vs p.G12V (B) Wild type vs p.G12C. 
cancers would be unlikely to affect the key findings of this study although the possibility of an under estimation of the magnitude of effect of KRAS mutation on overall survival cannot be discounted. In addition, this study did not assess other less common mutations in KRAS, NRAS or HRAS. The importance of these mutations has only been identified in the last few years (Douillard et al, 2013; Colussi et al, 2013), and KRAS-only testing was contemporary clinical practice at the time of analysis. Subgroup analysis of biologically important but relatively low incidence mutations such as G12A and codon 61 mutations may also not have sufficient numbers to achieve statistical power. This phenomenon is not unique to this study, and likely explains in discrepancies in the reported importance of uncommon mutations between series (Margonis et al, 2015; Kim et al, 2016; Passot et al, 2016). Metaanalysis will be required to better define clinical importance.

This study included patients who presented with stage IV disease, as well as patients who had undergone curative intent surgery. The overwhelming majority of patients who had undergone surgical resection developed recurrence, reflecting the selection of this group for KRAS testing, and so the number of patients 'cured' by surgery was low. Patient characteristics were well matched between these groups, with concordance between primary and metastatic tumours in other key oncogenic mutations (such as NRAS, BRAF, PIK3CA and TP53) of over $90 \%$ (Vakiani et al, 2012), and so it seems the potential impact of this mixed cohort is likely limited. In addition, the key findings of this study are in line with the findings of the PETACC8 trial in stage III (non-metastatic) colorectal cancer that showed codon $12 / 13$ mutations were associated with shorter time to recurrence after curative intent surgery (Blons et al, 2014).

The other major limitation of the current study surrounds the lack of data on subsequent cancer treatment. It is well recognised that treatment with systemic chemotherapy can have a significant impact on disease progression and overall survival in metastatic colorectal cancer, and it is impossible to exclude potential differences in treatments between subgroups, although all patients would have been treated according to contemporary UK NICE guidance (Poston et al, 2011). In addition, the proportion of patients treated with curative intent surgery were the same for each subgroup based on KRAS status. If patients are considered fit enough to tolerate curative intent surgery, it seems likely that they would be fit enough to receive systemic chemotherapy. The prognostic advantage enjoyed by KRAS wild-type tumours may also be partly explained by the use of antiEGFR therapy. However, during the study period this was limited by UK NICE guidance to liver-limited irresectable metastatic disease (NICE (National Institute for Health and Care Excellence), 2009).

In conclusion, this study clearly demonstrates that mutations in KRAS codon 12 are independently associated with overall survival in recurrent and metastatic colorectal cancer, with specific somatic mutations within codon 12 (p.G12V and p.G12C) appearing to be prognostically deleterious. Analysis of KRAS mutation status may help guide clinical decision-making and prognostication in patients with advanced and recurrent colorectal cancer.

\section{CONFLICT OF INTEREST}

The authors declare no conflict of interest.

\section{REFERENCES}

Al-Mulla F, Milner-White EJ, Going JJ, Birnie GD (1999) Structural differences between valine-12 and aspartate-12 Ras proteins may modify carcinoma aggression. J Pathol 187: 433-438.

Andreyev HJ, Norman AR, Cunningham D, Oates J, Dix BR, Iacopetta BJ, Young J, Walsh T, Ward R, Hawkins N, Beranek M, Jandik P, Benamouzig R, Jullian E, Laurent-Puig P, Olschwang S, Muller O, Hoffmann I, Rabes HM,
Zietz C, Troungos C, Valavanis C, Yuen ST, Ho JW, Croke CT, O'Donoghue DP, Giaretti W, Rapallo A, Russo A, Bazan V, Tanaka M, Omura K, Azuma T, Ohkusa T, Fujimori T, Ono Y, Pauly M, Faber C, Glaesener R, de Goeij AF, Arends JW, Andersen SN, Lövig T, Breivik J, Gaudernack G, Clausen OP, De Angelis PD, Meling GI, Rognum TO, Smith R, Goh HS, Font A, Rosell R, Sun XF, Zhang H, Benhattar J, Losi L, Lee JQ, Wang ST, Clarke PA, Bell S, Quirke P, Bubb VJ, Piris J, Cruickshank NR, Morton D, Fox JC, Al-Mulla F, Lees N, Hall CN, Snary D, Wilkinson K, Dillon D, Costa J, Pricolo VE, Finkelstein SD, Thebo JS, Senagore AJ, Halter SA, Wadler S, Malik S, Krtolica K, Urosevic N (2001) Kirsten ras mutations in patients with colorectal cancer: the 'RASCAL II' study. Br J Cancer 85: 692-696.

Bazan V, Migliavacca M, Zanna I, Tubiolo C, Grassi N, Latteri MA, La Farina M, Albanese I, Dardanoni G, Salerno S, Tomasino RM, Labianca R, Gebbia N, Russo A (2002) Specific codon 13K-ras mutations are predictive of clinical outcome in colorectal cancer patients, whereas codon 12K-ras mutations are associated with mucinous histotype. Ann Oncol 13: 1438-1446.

Blons H, Emile JF, Le Malicot K, Julié C, Zaanan A, Tabernero J, Mini E, Folprecht G, Van Laethem JL, Thaler J, Bridgewater J, Nørgård-Petersen L, Van Cutsem E, Lepage C, Zawadi MA, Salazar R, Laurent-Puig P, Taieb J, PETACC-8 Study Investigators (2014) Prognostic value of KRAS mutations in stage III colon cancer: post hoc analysis of the PETACC8 phase III trial dataset. Ann Oncol 25: 2378-2385.

Bokemeyer C, Bondarenko I, Makhson A, Hartmann JT, Aparicio J, de Braud F, Donea S, Ludwig H, Schuch G, Stroh C, Loos AH, Zubel A, Koralewski P (2009) Fluorouracil, leucovorin, and oxaliplatin with and without cetuximab in the first-line treatment of metastatic colorectal cancer. J Clin Oncol 27: 663-671.

Cancer Genome Atlas Network (2012) Comprehensive molecular characterization of human colon and rectal cancer. Nature 487: 330-337.

Castagnola P, Giaretti W (2005) Mutant KRAS, chromosomal instability and prognosis in colorectal cancer. Biochim Biophys Acta 1756: 115-125.

Colussi D, Brandi G, Bazzoli F, Ricciardiello L (2013) Molecular pathways involved in colorectal cancer: implications for disease behavior and prevention. Int J Mol Sci 14: 16365-16385.

De Roock W, Jonker DJ, Di Nicolantonio F, Sartore-Bianchi A, Tu D, Siena S, Lamba S, Arena S, Frattini M, Piessevaux H, Van Cutsem E, O'Callaghan CJ, Khambata-Ford S, Zalcberg JR, Simes J, Karapetis CS, Bardelli A, Tejpar S (2010) Association of KRAS p.G13D mutation with outcome in patients with chemotherapy-refractory metastatic colorectal cancer treated with cetuximab. JAMA 304: 1812-1820.

Douillard J-Y, Oliner KS, Siena S, Tabernero J, Burkes R, Barugel M, Humblet Y, Bodoky G, Cunningham D, Jassem J, Rivera F, Kocákova I, Ruff P, Błasińska-Morawiec M, Šmakal M, Canon JL, Rother M, Williams R, Rong A, Wiezorek J, Sidhu R, Patterson SD (2013) Panitumumab-FOLFOX4 treatment and RAS mutations in colorectal cancer. N Engl J Med 369: 1023-1034.

Downward J (2003) Targeting RAS signalling pathways in cancer therapy. Nat Rev Cancer 3: 11-22.

Fearon ER (2011) Molecular genetics of colorectal cancer. Annu Rev Pathol 6: 479-507.

Guerrero S, Casanova I, Farré L, Mazo A, Capellà G, Mangues R (2000) K-ras codon 12 mutation induces higher level of resistance to apoptosis and predisposition to anchorage-independent growth than codon 13 mutation or proto-oncogene overexpression. Cancer Res 60: 6750-6756.

Imamura Y, Lochhead P, Yamauchi M, Kuchiba A, Qian ZR, Liao X, Nishihara R, Jung S, Wu K, Nosho K, Wang YE, Peng S, Bass AJ, Haigis KM, Meyerhardt JA, Chan AT, Fuchs CS, Ogino S (2014) Analyses of clinicopathological, molecular, and prognostic associations of KRAS codon 61 and codon 146 mutations in colorectal cancer: cohort study and literature review. Mol Cancer 13: 135.

Imamura Y, Morikawa T, Liao X, Lochhead P, Kuchiba A, Yamauchi M, Qian ZR, Nishihara R, Meyerhardt JA, Haigis KM, Fuchs CS, Ogino S (2012) Specific mutations in KRAS codons 12 and 13, and patient prognosis in 1075 BRAF wild-type colorectal cancers. Clin Cancer Res 18: 4753-4763.

Janakiraman M, Vakiani E, Zeng Z, Pratilas CA, Taylor BS, Chitale D, Halilovic E, Wilson M, Huberman K, Ricarte Filho JC, Persaud Y, Levine DA, Fagin JA, Jhanwar SC, Mariadason JM, Lash A, Ladanyi M, Saltz LB, Heguy A, Paty PB, Solit DB (2010) Genomic and biological characterization of exon 4 KRAS mutations in human cancer. Cancer Res 70: 5901-5911. 
Karnoub AE, Weinberg RA (2008) Ras oncogenes: split personalities. Nat Rev Mol Cell Biol 9: 517-531.

Kim HS, Heo JS, Lee J, Lee JY, Lee MY, Lim SH, Lee WY, Kim SH, Park YA, Cho YB, Yun SH, Kim ST, Park JO, Lim HY, Choi YS, Kwon WI, Kim HC, Park YS (2016) The impact of KRAS mutations on prognosis in surgically resected colorectal cancer patients with liver and lung metastases: a retrospective analysis. BMC Cancer 16: 120.

Kudryavtseva AV, Lipatova AV, Zaretsky AR, Moskalev AA, Fedorova MS, Rasskazova AS, Shibukhova GA, Snezhkina AV, Kaprin AD, Alekseev BY, Dmitriev AA, Krasnov GS (2016) Important molecular genetic markers of colorectal cancer. Oncotarget 7: 53959-53983.

Li W, Qiu T, Zhi W, Shi S, Zou S, Ling Y, Shan L, Ying J, Lu N (2015) Colorectal carcinomas with KRAS codon 12 mutation are associated with more advanced tumor stages. BMC Cancer 15: 340.

Margonis GA, Kim Y, Spolverato G, Ejaz A, Gupta R, Cosgrove D, Anders R, Karagkounis G, Choti MA, Pawlik TM (2015) Association between specific mutations in KRAS codon 12 and colorectal liver metastasis. JAMA Surg 150: 722-729.

Neumann J, Zeindl-Eberhart E, Kirchner T, Jung A (2009) Frequency and type of KRAS mutations in routine diagnostic analysis of metastatic colorectal cancer. Pathol Res Pract 205: 858-862.

NICE (National Institute for Health and Care Excellence) (2009) Cetuximab for First Line Treatment of Metastatic Colorectal Cancer. Technology Appraisal Guideline TA176. Available at https://www.nice.org.uk/Guidance/TA176.

Ogino S, Fuchs CS, Giovannucci E (2012) How many molecular subtypes? Implications of the unique tumor principle in personalized medicine. Expert Rev Mol Diagn 12: 621-628.

Passot G, Denbo JW, Yamashita S, Kopetz SE, Chun YS, Maru D, Overman MJ, Brudvik KW, Conrad C, Aloia TA, Vauthey JN (2016) Is hepatectomy justified for patients with RAS mutant colorectal liver metastases? An analysis of 524 patients undergoing curative liver resection. Surgery 161: 332-340.

Poston GJ, Tait D, O'Connell S, Bennett A, Berendse S, On behalf of the Guideline Development Group (2011) Diagnosis and management of colorectal cancer: summary of NICE guidance. BMJ 343: d6751.

Pugh SA, Shinkins B, Fuller A, Mellor J, Mant D, Primrose JN (2016) Site and stage of colorectal cancer influence the likelihood and distribution of disease recurrence and postrecurrence survival: data from the FACS randomized controlled trial. Ann Surg 263: 1143-1147.

Rajagopalan H, Bardelli A, Lengauer C, Kinzler KW, Vogelstein B, Velculescu VE (2002) Tumorigenesis: RAF/RAS oncogenes and mismatch-repair status. Nature 418: 934.

Rosty C, Young JP, Walsh MD, Clendenning M, Walters RJ, Pearson S, Pavluk E, Nagler B, Pakenas D, Jass JR, Jenkins MA, Win AK, Southey MC, Parry S, Hopper JL, Giles GG, Williamson E, English DR, Buchanan DD (2013) Colorectal carcinomas with KRAS mutation are associated with distinctive morphological and molecular features. Mod Pathol 26: 825-834.

Roth AD, Tejpar S, Delorenzi M, Yan P, Fiocca R, Klingbiel D, Dietrich D, Biesmans B, Bodoky G, Barone C, Aranda E, Nordlinger B, Cisar L, Labianca R, Cunningham D, Van Cutsem E, Bosman F (2010) Prognostic role of KRAS and BRAF in stage II and III resected colon cancer: results of the translational study on the PETACC-3, EORTC 40993, SAKK 60-00 trial. J Clin Oncol 28: 466-474.

Samowitz WS, Curtin K, Schaffer D, Robertson M, Leppert M, Slattery ML (2000) Relationship of Ki-ras mutations in colon cancers to tumor location, stage, and survival: a population-based study. Cancer Epidemiol Biomarkers Prev 9: 1193-1197.

Smith G, Bounds R, Wolf H, Steele RJC, Carey FA, Wolf CR (2010) Activating K-Ras mutations outwith 'hotspot' codons in sporadic colorectal tumours - implications for personalised cancer medicine. Br J Cancer 102: 693-703.

Tejpar S, Celik I, Schlichting M, Sartorius U, Bokemeyer C, Van Cutsem E (2012) Association of KRAS G13D tumor mutations with outcome in patients with metastatic colorectal cancer treated with first-line chemotherapy with or without cetuximab. J Clin Oncol 30: 3570-3577.

Vakiani E, Janakiraman M, Shen R, Sinha R, Zeng Z, Shia J, Cercek A, Kemeny N, D’Angelica M, Viale A, Heguy A, Paty P, Chan TA, Saltz LB, Weiser M, Solit DB (2012) Comparative genomic analysis of primary versus metastatic colorectal carcinomas. J Clin Oncol 30: 2956-2962.

Van Cutsem E, Köhne C-H, Hitre E, Zaluski J, Chang Chien C-R, Makhson A, D'Haens G, Pintér T, Lim R, Bodoky G, Roh JK, Folprecht G, Ruff P, Stroh C, Tejpar S, Schlichting M, Nippgen J, Rougier P (2009) Cetuximab and chemotherapy as initial treatment for metastatic colorectal cancer. N Engl J Med 360: 1408-1417.

Van Cutsem E, Köhne C-H, Láng I, Folprecht G, Nowacki MP, Cascinu S, Shchepotin I, Maurel J, Cunningham D, Tejpar S, Schlichting M, Zubel A, Celik I, Rougier P, Ciardiello F (2011) Cetuximab plus irinotecan, fluorouracil, and leucovorin as first-line treatment for metastatic colorectal cancer: updated analysis of overall survival according to tumor KRAS and BRAF mutation status. J Clin Oncol 29: 2011-2019.

Yamauchi M, Morikawa T, Kuchiba A, Imamura Y, Qian ZR, Nishihara R, Liao X, Waldron L, Hoshida Y, Huttenhower C, Chan AT, Giovannucci E, Fuchs C, Ogino S (2012) Assessment of colorectal cancer molecular features along bowel subsites challenges the conception of distinct dichotomy of proximal versus distal colorectum. Gut 61: 847-854.

Yokota T, Ura T, Shibata N, Takahari D, Shitara K, Nomura M, Kondo C, Mizota A, Utsunomiya S, Muro K, Yatabe Y. (2011) BRAF mutation is a powerful prognostic factor in advanced and recurrent colorectal cancer. $\mathrm{Br}$ J Cancer 104: 856-862.

Yoon HH, Tougeron D, Shi Q, Alberts SR, Mahoney MR, Nelson GD, Nair SG, Thibodeau SN, Goldberg RM, Sargent DJ, Sinicrope FA, Alliance for Clinical Trials in Oncology (2014) KRAS codon 12 and 13 mutations in relation to disease-free survival in BRAF-wild-type stage III colon cancers from an adjuvant chemotherapy trial (N0147 alliance). Clin Cancer Res 20: 3033-3043.

This work is published under the standard license to publish agreement. After 12 months the work will become freely available and the license terms will switch to a Creative Commons AttributionNonCommercial-Share Alike 4.0 Unported License. 